\section{Relative discriminability of visually-presented letter pairs using a same-different choice-reaction time task}

\author{
DAVID E. CLEMENT and JAMES S. CARPENTER \\ University of South Florida, Tampa, Fla. 33620
}

Twenty-three pairs of capital letters representing the four combinations of high and low visual and auditory similarity, and 17 pairs of identical letters were used as stimuli in a same-different choice-reaction time task. Eight Ss (four of each sex) performed on 780 discrimination trials. Results indicated that same-different judgments were made essentially on the basis of visual characteristics, with letter pairs of high visual similarity having slower RTs than pairs of low visual similarity. Left-to-right order of letters in a pair had no effect, nor did auditory similarity. "Same" judgments had a more restricted range of RT and tended to be slower than "different" judgments.

\begin{abstract}
Various studies concerning the encoding of stimuli by a human observer have been directed toward the form of the encoded stimulus in various neural "storage" processes. Some authors have provided evidence for the claim that visual input is available as such for only $1-2 \mathrm{sec}$, while subsequent encoding and storage of visual information is in the form of an auditory analogue (e.g., Sperling, 1963; Conrad, 1964; Wickelgren, 1965; Hintzman, 1967). Other investigators obtained evidence of long-term storage of such information in a visual form (e.g., Shepard, 1967; Dallet, Wilcox, \& D'Andrea, 1968; Monty, 1968).
\end{abstract} Tversky (1969) attempted a resolution of this conflict by investigating encoding of both verbal and pictorial material. She concluded that the encoding of either type of material may be either verbal (auditory) or pictorial (visual) depending upon the S's anticipation of what he is to do with such material. One problem in such studies is related to the selection of stimuli. In those studies using letters of the alphabet, this selection has been on a rather arbitrary basis, involving only a priori judgments by the $E$ of the type and extent of auditory and visual similarity among those letters chosen for study. The most elegant was that of Conrad (1964), in which 10 letters were used, five in each of two sets judged to be acoustically similar within sets but not between sets. The confusion matrices for visual and auditory recall were similar, and this was interpreted as favoring an auditory storage hypothesis. Unfortunately, no evaluation of possible visual similarity within and between sets of letters was made prior to the experiment, so the results are confounded with possible differences in visual similarity.

This study was concerned with evaluating the relative discriminability of a series of pairs of letters representing the four possible combinations of high and low visual similarity and high and low auditory similarity. As choice-reaction time (RT) has been shown to be a function of the similarity of stimuli to be presented (e.g., Thurmond \& Alluisi, 1963), this dependent measure was used in a same-different judgment task with visually presented stimuli.

\section{Categorization of Letter Pairs}

Ss were four males and one female, including two faculty members, one graduate student, and two undergraduate students in psychology. About 40 letter pairs were selected that seemed to include the four possible combinations of low and high visual similarity and low and high auditory similarity. Each $\mathrm{S}$ was asked to assign each letter pair to one of the categories representing these four combinations. The 23 letter pairs in Table 1 are those for which there was unanimous agreement as to assignment. Same-Different RT Task

Eight undergraduate volunteers (four males and four females) from an introductory psychology course were used as Ss. All had normal vision uncorrected, and all had English as their native language.

The stimuli were pairs of upper case letters $4 \mathrm{~mm}$ in height (Letraset No. 193). Each pair of these black letters was centered on the visible portion of a $5 \times 8$ in. $(12.7 \times 20.3 \mathrm{~cm})$ white card. The space between letters in a pair was $4 \mathrm{~mm}$. At a viewing distance of approximately $43 \mathrm{~cm}$, each pair of letters subtended a visual angle of about $1.6 \mathrm{deg}$. Thus, all stimuli were presented foveally. Forty pairs of letters were used as stimuli, including the 23 pairs of different letters shown in Table 1 and 17 pairs of identical letters (all 17 individual letters appearing in Table 1). Stimuli were presented through a Polymetric two-field mirror tachistoscope. RT was measured by a Hunter
Klockounter. Ss wore earphones through which white noise was channeled at approximately $30 \mathrm{~dB}$ (re .0002 dynes $/ \mathrm{cm}$ squared). A Hewlett-Packard tone generator was used to produce a warning tone of $650 \mathrm{~Hz}$ at about $40 \mathrm{~dB}$ in the earphones.

The $S$ was seated in front of the tachistoscope with each index finger resting on a response key. A small "plus sign" was used as a fixation point during the interval between stimulus exposures. Each trial was initiated by a $1-\mathrm{sec}$ warning tone; onset of the stimulus coincided with offset of this tone. The stimulus was exposed for $1 \mathrm{sec}$, and the intertrial interval was $8 \mathrm{sec}$. Each $\mathrm{S}$ was instructed to press one key when the two letters were the same and the other key when the two letters were different. "Same" and "different" keys were counterbalanced across Ss, all of whom were right-handed.

Each $S$ was given a total of 800 trials. An initial practice session included 20 trials using letters not in Table 1. The subsequent 780 trials were divided into six blocks of 130 trials, two blocks per day for 3 days. Each block of trials contained 10 repetitions each of the 13 possible ordered pairs of letters from one of the following six lists: (1) PB, PR, PE, PU; (2) BE, BR, $\mathrm{BT}, \mathrm{BW}$; (3) CG, CO, CT, CY; (4) DB, DO, DT, DM; (5) ET, EF, EZ, EO; and (6) GC, GQ, GZ, GN. The lists were constructed by selecting one pair of letters from each cell of Table 1, with the additional restriction that one of the letters appear in all four pairs. This restriction meant that each comparison within a list was partially independent of encoding differences for individual letters. The 130 trials in each block were randomized with the restriction that the same letter pair could not occur more than two times in succession. Thus, 80 of the pairs in each block included different letters (10 trials each of each left-to-right order of the four different letter pairs), while 50 included the same letters (10 trials each for pairs of the five

Table 1

Judged Classification of Letter Pairs

\begin{tabular}{|c|c|c|}
\hline & \multicolumn{2}{|c|}{$\begin{array}{c}\text { Visual } \\
\text { Similarity }\end{array}$} \\
\hline & High & Low \\
\hline \multirow{2}{*}{ Auditory Similarity } & $\begin{array}{l}\text { BD } \\
\text { BE } \\
\text { BP } \\
\text { CG } \\
\text { ET } \\
\text { EZ }\end{array}$ & $\begin{array}{l}\text { BT } \\
\text { CT } \\
\text { DT } \\
\text { EP } \\
\text { GZ }\end{array}$ \\
\hline & $\begin{array}{l}\text { BR } \\
\text { CO } \\
\text { DO } \\
\mathrm{EF} \\
\text { GQ } \\
\text { PR }\end{array}$ & $\begin{array}{l}\text { BW } \\
\text { CY } \\
\text { DM } \\
\text { EO } \\
\text { GN } \\
\text { PU } \\
\end{array}$ \\
\hline
\end{tabular}


Table 2

"Different" Reaction Times

\begin{tabular}{lcccc}
\hline $\begin{array}{c}\text { Letter } \\
\text { Pair }\end{array}$ & $\begin{array}{c}\text { Visual/Auditory } \\
\text { Similaritya }\end{array}$ & $\begin{array}{c}\text { Mean of Median } \\
\text { RTs (Msec) }\end{array}$ & $\begin{array}{c}\text { Mean of Mean } \\
\text { RTs (Msec) }\end{array}$ & $\begin{array}{c}\text { Mean Standard } \\
\text { Error of Meanb }\end{array}$ \\
\hline EF & H/L & 505 & 509 & 19.8 \\
CG & H/H & 486 & 487 & 13.5 \\
GQ & H/L & 482 & 478 & 17.9 \\
CO & H/L & 473 & 472 & 18.6 \\
BR & H/L & 471 & 471 & 17.3 \\
BP & H/H & 470 & 468 & 19.1 \\
DO & H/L & 456 & 460 & 16.7 \\
PR & H/L & 451 & 455 & 19.8 \\
BD & H/H & 444 & 442 & 18.2 \\
EZ & H/H & 438 & 440 & 17.4 \\
BE & H/H & 438 & 434 & 17.9 \\
GN & L/L & 430 & 434 & 16.0 \\
ET & H/H & 428 & 436 & 17.0 \\
BW & L/L & 417 & 422 & 18.1 \\
EO & L/L & 414 & 421 & 16.8 \\
CT & L/H & 410 & 413 & 15.8 \\
PU & L/L & 405 & 408 & 15.2 \\
EP & L/H & 399 & 408 & 16.7 \\
DT & L/H & 396 & 399 & 17.9 \\
BT & L/H & 394 & 399 & 15.1 \\
DM & L/L & 393 & 393 & 16.9 \\
GZ & L/H & 387 & 400 & 14.6 \\
DY & L/L & 383 & 390 & 15.3 \\
\hline
\end{tabular}

$a_{L}=$ low, $H=$ high

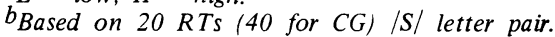

different letters). Instructions to the Ss emphasized the importance of accuracy and asked the Ss to respond as rapidly as possible while making no errors. During the trials, the Ss were given no feedback as to RT but were told when errors had occurred. Stimuli to which a $\mathrm{S}$ responded incorrectly were repeated subsequently within the same trial block.

\section{RESULTS}

As the RTs were positively skewed for all Ss, median RT for each $S$ on each stimulus was considered the most appropriate indicator of discriminability. There were no significant differences in order (e.g., between EF and FE), so values for both orders for each pair of different letters were pooled. Table 2 contains the pairs of different letters, ordered as to increasing discriminability, the cell from Table 1 to which each belongs (indicating

Table 3

\begin{tabular}{cc} 
"Same" & Reaction \\
\hline $\begin{array}{c}\text { Letter } \\
\text { Pair }\end{array}$ & $\begin{array}{c}\text { Mean of Median } \\
\text { RTs (Msec) }\end{array}$ \\
\hline GG & 479 \\
NN & 467 \\
YY & 463 \\
UU & 462 \\
ZZ & 457 \\
PP & 454 \\
QQ & 454 \\
TT & 452 \\
BB & 451 \\
WW & 450 \\
CC & 442 \\
FF & 440 \\
OO & 440 \\
RR & 438 \\
MM & 434 \\
DD & 430 \\
EE & 428 \\
\hline
\end{tabular}

judged visual and auditory similarity), and the mean values (across Ss) for median RT, mean RT, and standard error of mean RT (population estimate). Although means and variances are correlated, a reasonable modal figure for the standard error of the mean is about $17 \mathrm{msec}$. Thus, RT values which differ by $47 \mathrm{msec}$ or more could be considered reliably different at the .05 level.

Based upon the median RT values, letter pairs that are high in visual similarity are more difficult to discriminate than those low in visual similarity. Acoustic similarity does not seem to have any consistent effect. Only the reversed order of GN and ET prevents the dimension of visual similarity from being used alone for perfect dichotomous prediction of discriminability. This ordering was consistent within Ss as well. The rank order correlations of median RTs between pairs of Ss ranged from .47 to .86 (Spearman's rho) for seven of the eight Ss. The eighth $\mathrm{S}$ (a male) correlated between .34 and .70 with each of the others. The average inter-S correlation was .67 , indicating reasonable consistency.

The mean values of median RTs for "same" judgments ranged from 428 to $479 \mathrm{msec}$, with an overall mean of $450 \mathrm{msec}$, as shown in Table 3. This was slower than the overall mean of median RTs for "different" judgments (434 msec). This difference is difficult to interpret, as the range for "different" judgments was greater and completely included that for "same" judgments, and the difference was confounded in this experiment with relative frequency of occurrence (300 trials with identical letters, 480 trials with different letters in a pair).

The assumption might be made that "same" judgments reflect relative ease of encoding for individual letters. Thus, "different" RTs would include two factors, the ease of encoding of each letter plus a factor reflecting discriminability between the two letters in a pair. Therefore, the mean value for median RTs on "same" judgments for the two letters in a pair was correlated with the mean value of median RTs for "different" judgments for that pair across all pairs of letters. The rank order correlation (Spearman's rho) was -.03 , indicating no effect of relative encoding for individual letters. Error rate was extremely low (less than $2 \%$ ), so errors were not submitted to any analysis.

\section{DISCUSSION}

The results of this experiment strikingly support the notion of a visually based match of visually presented material in a same-different choice-reaction time task. In addition, for this kind of task, the effects of auditory characteristics appear minimal. However, this remains consonant with theories suggesting auditory encoding of visual information (e.g., Sperling, 1963), for the RTs were generally less than $500 \mathrm{msec}$, and none of the auditory theories denies the existence of information available in a visual form during the first $1 \mathrm{sec}$ or so after presentation. The outcome of the experiment is important for two reasons. First, it stresses the importance of visual similarity in such a task, even when there are obvious auditory features in the stimuli. Second, the values for relative discriminability of the letter pairs provide a means for controlling these basic initial differences in future studies with visually presented letter pairs, so that subsequent encoding steps may be assessed more accurately as to the contributions of visual, auditory, or other factors.

Humans, in a visual matching task such as this, rely primarily upon visual characteristics of the stimuli. Im more complex tasks, such as recall or extended search, it is reasonable to posit that the first steps in encoding also will involve processing of essentially visual characteristics.

\section{REFERENCES}

CONRAD, R. Acoustic confusions in immediate memory. British Journal of Psychology. 1964, $55,75-84$

DALLETT, K., WILCOX, S. G., \& D'ANDRFA, L. Picture memory experiments. Journal of Experimental Psychology, 1968, 76, 312-320. HINTZMAN, D. L. Articulatory coding in short-term memory. Journal of Verbal L.earning \& Verbal Behavior, 1967, 6, 312-316. MONTY, R. A. Spatial encoding strategies in sequential short-term memory. Journal of 


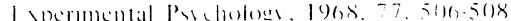
SHIP P ARI), R. D. Re(o)mition memory for

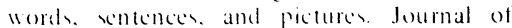
lerbal larmme de liobal Behavior. 1967.6. $156 \cdot 16.3$

SPI RIING, (i. A model for visual memory lasks. Human laciors 1963,5,19-31.

IHLRMOND. J. B., \& AI.LIISI. I. A. (holec time as a function of stimulus dissmilarity and

\title{
Weight judgment as a function of apparent density of objects*
}

\author{
STEPHEN P. HARSHFIELD and DORIS C. DeHARDT $\dagger$ \\ California State College, Long Beach, Calif. 90801
}

Five cubes of equal size and weight made of balsa wood, mahogany, aluminum, brass, and steel were ranked from heaviest to lightest in the above order by Ss who lifted each of these cubes, while Ss who ranked the cubes visually reported the reverse order, as their apparent density would prescribe. Phenomenologically the present results, which might be called a density-weight illusion, are quite similar to those of the size-weight illusion.

The familiar size-weight illusion dramatically illustrates the effect of size on the judged weight of objects (Crutchfield, Woodworth, \& Albrecht, 1955). The differential effects of brightness and hue on the apparent weight of objects have also been reported (Harshfield \& Shaumburg, 1964; Monroe, 1925; Payne, 1961). Harshfield and Shaumburg found that stimulus objects of equal size and weight were judged lighter in direct relation to their brightness.

In the present study the apparent composition of objects was manipulated with the expectation that cubes of equal size and weight would be judged inversely, i.e., heavier, with their apparent density. Thus, a lifted cube made of balsa wood was expected to be judged heavier than one made of, say, brass. It was predicted that cubes of equal size and weight made of balsa wood, mahogany, aluminum, brass, and steel would be ranked heaviest to lightest in that order by Ss lifting each of these cubes, but that Ss ranking the cubes visually would report the reverse order. This phenomenon of judgmental reversal might be called a density-weight illusion.

\section{SUBJECTS}

Ninety volunteers from introductory

*Based on the senior author's thesis submitted to California State College, Long Beach in partial fulfillment of requirements of the MA degree.

$\div$ The authors appreciate the assistance of Henry Michalewski with the manuscript. Requests for reprints should be sent to Doris C. DeHardt. Department of Psychology. California state College. L ong Beach, Calif. 90801. (iiscriminabllaty (anadian Journal of Pavchology. 1963, 17, 326-337.

IVIRSKY. B. Pictorial and verbal encodeng in a short-term memory task. Perception \&

WIC KILGRIN, W. A. Acoustic similarity and intrusion errors in short-term memory. Journal of lixperimental Psychology, 1965, 70. 102-108. Puchophysics, 1969.6. 225-233. psychology classes at California State College, Long Beach, served as Ss.

\section{APPARATUS}

The stimuli were five $1 \frac{1}{2}-$ in. cubes made of balsawood, mahogany, aluminum, brass, and steel. The cubes were bored out and/or filled with lead shot as was necessary to make each weigh $5 \mathrm{oz}(143 \pm 2 \mathrm{~g})$. Masking tape covered the altered area on the bottom of each cube. A piece of beige felt covered the table upon which the cubes were placed during the experiment. Rubber glove fingers that covered to the first knuckle were used for Ss in the lifting conditions and a blindfold was used for the control group.

\section{PROCEDURE}

The 90 Ss were divided randomly into three groups of 30 each. One group, the visual group, ranked the cubes only by looking at them; another group, called the lift group, ranked the cubes after lifting while looking; a control group lifted while blindfolded. Ss in the groups involved in lifting werc asked to use their dominant hands.

Each $S$ was seated comfortably at a table and given instructions in the task which included that the cubes were to be ranked from heaviest to lightest, one through five. No ties were permitted in the judgments and no time restraint was set for the task. In the conditions involving lifting, Ss were told to lift the cubes before them, singly, working from left to right and then to start over again so that each cube would be lifted twice. Ss were told to lift only with their covered fingers (thumb and first and second fingers), to keep their elbows on the table, to lift a cube in one smooth decisive motion (for a distance of about 6 in.), and not to dangle the cube at the top of a lift but to replace it immediately. In the visual group Ss were permitted to look at the cubes as long as they liked before making their rankings. In the visual and lift groups announcement of rankings was made by S's pointing at the cube that seemed heaviest, then the next heaviest, and so on; control Ss used verbal explanations, such as "the second cube from the left is heaviest," to indicate their rankings.

Different random orders of left-to-right placement of cubes were used for all Ss.

\section{RESULTS AND DISCUSSION}

The means and standard deviations of rankings for Ss in each of the three groups are presented in Table 1. To determine the degree of inter-S agreement for Ss in each condition, Kendall's coefficient of concordance, $\mathrm{W}$, was computed for each group. The results of this analysis are also shown in Table 1.

To determine whether the differences in mean ranks between each adjacent pair of cubes in each condition were statistically significant, sign tests for related samples were performed. For a particular cube pair in a particular condition the number of Ss reporting one cube heavier than the other was determined and formed the basis of the sign test on that pair. Thus, for statistical purposes, each adjacent pair was regarded as an independent comparison for Ss. The sign test results, in normal

Table 1 Means and Standard Deviations of Ranks and W's for the Five Cubes in Each Group

\begin{tabular}{|c|c|c|c|c|c|c|}
\hline \multirow[b]{3}{*}{ Cube } & \multicolumn{4}{|c|}{ Experimental Group } & & \\
\hline & \multicolumn{2}{|c|}{$\begin{array}{c}\text { Visual } \\
W=.746 \\
p<.001\end{array}$} & \multicolumn{2}{|c|}{$\begin{array}{c}\text { Lift } \\
W=.445 \\
p<.001\end{array}$} & \multicolumn{2}{|c|}{$\begin{array}{c}\text { Control } \\
\mathrm{W}=.004\end{array}$} \\
\hline & $\mathrm{M}$ & SD & $\mathrm{M}$ & SD & $\mathrm{M}$ & $\mathrm{SD}$ \\
\hline Steel & 1.20 & .42 & 4.00 & 1.13 & 3.06 & 1.29 \\
\hline Brass & 2.00 & .65 & 3.70 & 1.02 & 3.20 & 1.22 \\
\hline Aluminum & 3.40 & .85 & 3.50 & .95 & 3.10 & 1.32 \\
\hline Mahogany & 3.50 & .61 & 2.10 & .81 & 2.96 & 1.52 \\
\hline Balsa Wood & 4.70 & .73 & 1.63 & 1.01 & 2.96 & 1.62 \\
\hline
\end{tabular}

